\title{
ALIENATION AND DIALECTICAL LOGIC ${ }^{1}$
}

\author{
Harry K. Wells
}

This paper discusses the principles of dialectical logic as developed in the works of Hegel and Marx. The author demonstrates how classical logic (or formal logic) is primarily a logic of classification and how dialectical logic was developed for the analysis of process or change. The laws of classificatory logic are preserved in dialectical logic by formulation of three levels of a dialectical syllogism: the first is concerned with the three stages of development, beginning, middle and end, in terms of quantitative and qualitative changes; the second is concerned with the interconnections of content and form as a quality, thing or thought moves from its beginning through its middle to its end; and the third is concerned with the negation of the negation of the laws of formal logic. The dialectical syllogism is applied to the problem of human history and the development of human society by tracing the development of alienation in the evolution of the structure of society. History is divided into three main stages: 1) The Age of Gathering, which is characterized by non-antagonistic contradictions; 2) The Age of Production, which is characterized by the heightening of antagonistic contradiction (the age of anxiety and alienation); and 3) The Age of creativity which is a new stage characterized by non-antagonistic contradictions.

In Western Europe and North America it has become fashionable to characterize the 20th century by the descriptive term "alienation." By "alienation" is meant the estrangement of man from nature, from fellow men, from society, from ethical and esthetic values, from reason, from, that is, the entire range of human relationships and capacities that constitute human nature. The core of alienation is then said to be the loss of identity of oneself as a human being.

The classified description of alienation in all its apparently endless forms gives rise to one or another type of multiple factor theory of the causality of the phenomenon. Alienation is attributed to a nexus of factors including industrialization, technology, science, the profit system of economy, urbanization, mass man, mass media, the giant impersonal state and corporation, conformity, individualism, collectivism and so on. These factors, with here more emphasis on one, there on another, are said to form the class of alienating conditions. They are the social, economic and historical circumstances that give rise to the individual feelings of estrangement characteristic of 20 th century man: anxiety, hostility, aloneness, hopelessness, powerlessness, meaninglessness and so on. These feelings comprise the psychological syndromes of alienation variously termed "the maladie du siecle," "the age of anxiety," "the human predicament," or "the neurotic personality of our time."

The factorial conditions and the symptomatic syndromes are the two most general classes under one or the other of which the sub-classes of the phenomena

1972 copyright by the author 
of alienation are subsumed. This classificatory approach almost invariably leads either to the optimistic proposal of a romantic return to some presumably more integrated kind of social-individual community or to the pessimistic prediction of a garrison state with imposed integration leading ultimately to total atomic destruction. Even when the solution is seen to lie in some form of "socialism," the welter of variously classified phenomena of alienation provides no structural approach that could indicate how such a system could be achieved. The "socialist" solution of alienation thereby becomes utopian. The romanticism of the two optimistic solutions -- the return to previous forms of integration and the advance to utopian socialism -- readily give way to the pessimism of the totalitarian and nuclear annihilation. The general conclusion from the classificatory analysis is that alienation is the price man pays for progress and therefore is a salient feature of the human condition. A historically constituted phenomena is thus transformed into a metaphysical principle: the principle of absurdity, namely that the more man adapts the environment to his needs and aspirations the more divorced he becomes from both the environment and himself. Such a conclusion is writ large and most graphically in the philosophy of existentialism, in the psychology of psychoanalysis, in the theatre of the absurd and in the novel of the alienated man.

1.

The first step in understanding any phenomenon is the classification of the subject matter. In a similar manner the first stage of any science is classification. For example, in botany and biology the first stage lasting some 2500 years was the classification of plants and animals; in astronomy the classification of stellar bodies; in history the classification of kinds of societies; and in psychology the classification of psychic qualities. The philosophical categories relevant to this first stage of science were, among others: the static or unchanging; isolation and analysis without distortion; space as the room in which things exist; time as simple duration; motion as limited to locomotion; and causation as an external relation of push or pull.

The logic relevant to the first stage of the sciences was rooted in the principle of identity -- a phenomenon is what it is, A is A; the principle of contradiction -- a phenomenon cannot be at one and the same time what it is and what it is not, A is not not-A; and finally the principle of excluded middle -a phenomenon is either what it is or what it is not, either A or not-A. These principles are minimal requirements for the purposes of definition and classification and do in fact reflect actual levels of objective reality, including the material world, language, logic and thought. The logic based on the three principles was the logic of classification with its paired categories of class and member, genus and species, universal and individual, general and particular, quality and quantity, one and many, and so on. The structure of classes reflecting--in language --the structure of ontological levels was mirror-imaged in the classificatory syllogism; the major premise as the relation between genus and species, including and included, excluding and excluded classes; the minor premise as the relation between individual and species, member and class; and the conclusion as the inferred relation between individual and genus, member and including or excluding class.

Classificatory logic underlies the approach to the question of alienation as outlined earlier. It is thus the necessary first step of understanding the nature of the phenomenon. The organizing mutually exclusive classes of alienation and 
alienating conditions on the one hand, and under alienation the sub-organizing classes of existential alienation of the individual and the states or feelings of alienation of the individual on the other, together with the wealth of detailed specific classes subsumed under each, constitute an indispensable beginning in the attempt to understand alienation. The analysis into parts and the synthesis into external classificatory relationships organizes the myriad phenomena of alienation into a conceptual framework reflecting the various alienation into a conceptual framework reflecting the various simultaneous levels existing in the world and in the mind of man. The classificatory approach, however, is not explanatory or causal and does not therefore lead to understanding of alienation as a process with a beginning, middle and predictive end. It does not, in short, provide a structure of temporal or spatial internal interconnections which would guide man in dealing with the phenomenon in such a manner as ultimately to transform it. The point is not only to recognize and classify the varied aspects of alienation as a static human condition, but to know its causes and internal connections in order to change it.

The second stage of the investigation of any given phenomenon is to understand its origin, development and direction of movement, to understand it not only as a class with sub-classes, but as a process with sub-processes. The second stage of any science is likewise characterized by concentration on process with its equal emphasis on temporal and spatial intercommunications and internal and external interrelations. Over the course of the past 150 years almost. all the natural and social sciences have made the transition from the reflection of the classificatory structure of their subject matters to the reflection of their developmental structures: In astronomy with Kant and Laplace; in geology with Lye11; in logic with Hege1, Feuerbach and Marx; in history and political economy with Marx and Engels; in biology with Darwin; in physics with Einstein; in physiology of the higher nervous activity with Pavlov; and so on. As a matter of fact, mathematics was the first to move into the structural analysis of process with the development of the calculus by Leibnitz and Newton.

As formal or classificatory logic is the structure of classes in general, so genetic or dialectical logic is the structure of processes in general. In the attempt to understand alienation as a process, then, dialectical logic is, to say the least, helpful as a structural intellectual instrument. Here however intrudes a peculiar situation for dialectical logic has itself been a victim of alienation. 2 In view of this fact, familiarity with it cannot be assumed at any level, academic or otherwise. Before applying dialectical logic to the structuring of those sciences relevant to an understanding of alienation as a process, this logic must itself be structured.

\section{2 .}

What Hegel called "natural" logic, both classificatory and genetic, is embodied in language. Language is the reflection of reality in words (vocabulary of nouns, verbs, etc.) and in sentence structure (grammer). Natural logic is the reflection of reality in interrelated sentences structured into a line of argument (usually as an enthymeme syllogism). Over the two million years of human evolution man has had to deal existentially with classification and change and has therefore had to develop linguistic and logical reflection of both classes and processes. The science of logic, like the science of linguistics, came into existence very 
late in man's development, only during the past 3,000 years. The semantic fact that in the case of language there is a separate and distinct name for the science, i.e., linguistics, while in the case of logic the term is the same for both the phenomenon and the science, has caused some confusion on this subject.

The historical fact that the initial task of the sciences was the classification of their respective subject matters, led to the development first of the science of classificatory logic. Thus the first stage of the development of the science of logic was classificatory or formal logic. The second stage of the sciences, based on the task of understanding their subject matters as processes, led to the second stage of the science of logic, genetic or dialectical logic. As sciences, classificatory or formal and genetic or dialectical logic constitute two successive stages in the development of the science of logic as a whole. The general science of logic, with its two historically constituted stages, is the science of the structure of the structure of reality, including both the structure of the structure of the material world and of its reflection in human consciousness by means of natural language and natural logic. If logic as a whole (as far as it has developed at this time) is the structure of the structure of the world and of thought, then classificatory or formal logic is the structure of classes in general while genetic or dialectical logic is the structure of processes in general. Each stage of the science of logic underlies and is expressed in the relevant stage of all the sciences, physical and social.

As the science of the structure of process or change in general, dialectical logic is concerned with the syllogistic reflection of beginning or origin, middle or development, and end or transformation that occur, barring catastrophic accident, seriatim in any process. Dialectical logic penetrates into the structure of this syllogism on at least four levels, moving from appearance to essence to deeper and still deeper essence.

The first level of reflection of the genetic or dialectical syllogism of process or change is concerned with the three stages of development, beginning, middle and end, in terms of quantitative and qualitative changes. The syllogism here views the beginning or origin as the transformation of a qualitative change into quantitative change: A "new" thing or thought has come into being (originating obviously from a previous quantitative development) and begins to develop quantitatively. The middle phase of the syllogism is the quantitative development of the quality: The thing or thought remains the same only by changing and changes only by remaining the same. The end phase of the syllogism is the transformation of the quantitative change into a qualitative change: The thing or thought has remained the same only by changing and changing to the extent that it can change no more without changing into something else, a "new" quality.

There are several generalizations in regard to this first level of the dialectical syllogism. Among these are: (1) Every beginning is an end and every end is a beginning; (2) Between every beginning and end is a more or less extended development during which the quality remains the same in kind but changes in degree; (3) The concept of quantitative change includes in itself the principle of identity of formal or classificatory logic, but transformed in terms of process or change; (4) As a process, a thing or thought is an identity (A is A) only because it is changing in degree and changing in degree to the point at which it changes in kind, becoming a "new" identity (in which B is B); (5) The concept of 
quantitative change likewise preserves within dialectical logic the principle of contradiction since as long as a process is changing quantitatively it is not anything other than what it is ( $A$ is not not-A); (6) By the same token, the first level of the dialectical syllogism preserves the principle of excluded middle in the form of quantitative change during which the thing or thought is either this or that (either A or not-A); (7) While quantitative change preserves the three principles of formal logic, the dialectical syllogism reflects likewise the fact that identities come into being and go out of being, that they undergo qualitative change simply because they are what they are only by changing quantitatively to the point of transformation; (8) Finally, and by no means least important, what is a quantitative change at one level of reality is a qualitative change at another and what is a qualitative change at one level is a quantitative change at another -- this does not mean that it is arbitrary choice of abstraction that determines the kind of change involved, but rather that the abstractions of thought must, to be true, correspond to actual levels of reality.

The second level of the dialectical syllogism, penetrating more deeply into the structure of process, is concerned with the interconnections of content and form as a quality, thing or thought, moves from its beginning through its middle to its end. Involved here is one of the major categories of dialectical logic, namely, contradiction. The central feature of contradiction is that negation carries affirmation in itself and affirmation carries negation in itself. What is simultaneously negated and affirmed, and how these affirmations and negations take place, involves the interconnections between content and form.

In the beginning phase of the second or contradiction level of the dialectical syllogism, when a new quality comes into being and begins to develop quantitatively, this quality is viewed as a particular content united with a particular form, the particular form of that particular content. At the beginning the relation of form to content is one of conformation. By conformation is meant that the form allows for the development of the content. In the middle phase of the contradiction level of the dialectical syllogism, as the quality develops quantitatively, the form still conforms to the content allowing the latter to develop, but this very fact brings the content closer and closer to the point of non-conformation of form to content. The identity of a thing or concept can now be seen to consist not only in quantitative change but also in the fact that content and form remain the same. However, they remain the same only by moving from original conformation toward ultimate non-conformation of form to content. This is part of what is signified by the term "contradiction." There is a developing contradiction between content and form. The two cannot exist apart, but at the same time they exist together only by moving from conformation to non-conformation. The change is quantitative so long as there is the same contradiction within a thing or concept, and the dialectical principle of identity consists in both these aspects. The end phase of the second level of the dialectical syllogism is the point of transformation of quantitative change into qualitative change, the point at which the form passes over into non-conformation with the content. The content breaks out of the old form and brings into being a new form, one which conforms to the new level of the developing content. This is termed the resolution of the old contradiction and the establishment of a new one.

There are a number of generalizations relevant to this second level of the dialectical syllogism, the level of contradiction. Among them is: (1) The course 
of movement of the contradiction from its inception to its resolution. If each step in this movement is a partial resolution of the contradiction, if, that is, the point of non-conformation of form to content takes place at the moment of closest unity of the two, then the resolution of the contradiction is said to be non-explosive and the contradiction itself to be non-antagonistic. If on the other hand each step in the movement of the contradiction widens the gap between the form and the content, if, that is, the form moves in the opposite direction from the content, then the point of non-conformation of form to content takes place at the moment of sharpest disunity. In such an event the resolution of the contradiction is said to be explosive and the contradiction itself to be antagonistic. (2) Another generalization in regard to the contradictory level of the dialectical syllogism is concerned with the categories of negation and negation of negation. Both have to do with the point of qualitative transformation of form and content. The first negation is the bursting asunder or rejection of the form and the preservation or retention of the content. It is the "no" or negative of the form and the "yes" or affirmative of the content. This is the preservative or conservative aspect of the dialectic. The second negation, the negation of the first negation, is the sublation or raising and transforming of the content at a new level through release from the constricting confines of the old form and at the same time the establishment of a new form which initially conforms to the new level of content. This is the creative or emergence-ofnovelty aspect of the dialectic.

(3) The third and final level of the dialectical syllogism penetrates still further into the structure of process. Involved is the negation and negation of negation of the laws of classificatory or formal logic. Here the laws or principles are taken in the classical sense as ontological as well as logical, as laws of being as well as laws of thought, as, that is, laws of the material world reflected through language and logic in the laws of thought. Dialectical logic structures the two primary laws of classificatory logic, the laws of identity and contradiction, into content and form. The law of identity is the content and the law of contradiction is the form appropriate to the classificatory content of identity. Thus the law that a thing or thought is what it is, that $A$ is $A$, is the content that develops throughout the history of logic whether formal or dialectical. The law of contradiction, that a thing or thought is not what it is not, that $A$ is not not-A, is the form this content takes in the classificatory stage. So long as the primary task of the sciences was classification of subject matters, this form of the law of identity conformed to the content. The classificatory form of identity stated that $A$ is $A$ and is not any unspecified spatial or temporal not-A. A thing or thought is differentiated from all things or thoughts other than itself. The $A$ is a specific and particular A, while the not-A is unspecified and universal, including everything which $\mathrm{A}$ is not. It was not until the classificatory structures of the various sciences began to break down, when things were found that could not be classified as either this or that, that the classificatory form of identity came into non-conformation with the content of identity. The latter passed over from static class to dynamic process. In the science of logic this meant that identity as process or change required the rejection of the old form and the retention of the content, namely identity. This break-up of the old form and the freeing of 
identity from it; constitutes the first negation of the laws of formal logic. It is the affirmation of the content and the repudiation of the form. The second negation, the negation of the negation, is the sublation of the content, the raising and transforming of the old content of identity as a static class to the new level of the content of identity as a process having a beginning, middle and end. This new content of identity then required and brings into being a new form, one that conforms to process. This new form is the negation of the negation of the old form. It is on the one hand the rejection of the unspecified, universal not-A and on the other the sublation, the raising and transforming of the not-A, the transformation of the universal not-A into a specific temporal not-A of the identity A. The specific temporal not-A of $A$ is the particular past and particular future of $A$ as it changes from its beginning through its middle to its end.

The third level of the dialectical syllogism is concerned with the negation of the negation of the laws of formal logic. The principle of identity as process in its new form states that a thing or thought is what it is because it is what it was and what it is becoming. What it was and what it is becoming are specific opposites in the sense that the past is the opposite of the future. The new dialectical level of identity is then said to be an identity of opposites: A is $A$ because $A$ is a specific past not-A and a specific direction of change into the specific future not-A. The content of identity is retained but in a new form: Instead of being an identity excluding the universal temporal not-A, it is an identity including the specific temporal not-A. The cornerstone of dialectical logic is the principle or law of the identity of opposites. Dialectical logic includes classification within itself, but is the form of the classification of processes -- types or classes of processes. Dialectical logic is not a rejection of formal logic, but is rather the negation and negation of negation of it. The content of classification is preserved but is sublated and given a new form. The dialectical syllogism embodies this new conformation of form to content: The structure of the process of change from one class to another in which each class (or member) is itself a process with its own specific temporal not-A, its own specific past and specific directional future.

There are a number of generalizations in regard to the law of the identity of opposites: (1) The opposites comprising an identity interpenetrate, enter into and are an internal part of one another, to such an extent that the one cannot exist without the other. Separation is impossible without the destruction or distortion of the identity. (2) While the opposites cannot exist apart they likewise cannot exist together without changing one another. This is called the conflict of opposites within an identity. The identity will remain the same while changing quantitatively so long as it is composed of the same opposites. (3) The opposites, however, interpenetrate, conflict and change one another ultimately to the point of transformation. At this point of qualitative change the opposites destroy one another and in so doing negate the identity. At this point the content of the identity is sublated and a new pair of opposites constitutes the new identity. (4) Every identity is composed of a single pair of opposites, but each of these opposites is an identity composed of its specific opposites. (5) Thus within any identity there is an entire structure of identities of opposites, levels within levels, stages within stages of processes. (6) Syllogistically this would be reflected as the interconnection of syllogisms moving from the more general to the more particular, from the more abstract to the more concrete -or vice versa. This structure of identities of opposites, which may be logically 
reflected in interconnected syllogisms, can be presented graphically. (cf. Fig. A) (7) Within each pair of opposites there is one that is the determining element: It brings about qualitative changes in the other, while the latter acts back again on the former to induce quantitative changes. (This is indicated in Fig. A by the double and single arrows.) (8) Within any structure of identities of opposites there will be a pair of opposites comprising an identity which constitutes the motive force of the entire identical process. When it moves all others will ultimately move. (cf. Fig. A, motive force is indicated by boxed pair of opposites within identity opp. 6) (9) The pair of opposites constituting the motive force will be found within the structure of opposites subsumed under the determining element. (In Fig. A, under opp. 2) The motive force is the source of self-motion of the identity as a class, quality, thing or thought.

There are many interconnections among the three levels of the dialectical syllogism. For example, the determining element in any pair of opposites is the content at the level of contradiction while the determined element is the form. Again, what is an identity of opposites at one level is a contradiction at another. Finally, what is an identity of opposites at one level and a contradiction at another is in both cases a quantitative change during which the class, quality, thing or thought remains the same. Thus the content of the principle of identity is preserved, albeit in a sublated form, within dialectical logic.

The three levels of the dialectical syllogism, reflecting more and more essential levels of the structure of ontological process, are concerned explicitly with the temporal interconnections within a given identity between its specific past and specific future as they interpenetrate and conflict to comprise its ongoing present. The full dialectic, however, is found in the spatial interconnections between two inseparable identities. Each of these identities is a structure of pairs of opposites. Spatial interconnection of paired identities is concerned with the negation and negation of negation of the formal logical principles of identity and contradiction taken in their spatial signification. A class, quality or thing is what it is, A is A, and is not anything else, A is not not-A in which the not-A refers to all things existing outside or external to A. The formal logical spatial not-A is universal. It is a distinction between $A$ and all that is spatially not-A. The first negation of the universal spatial not-A is the rejection of the universal form and the retention of the content, the spatial not-A. The negation of this negation is the sublation of the spatial not-A. The negation of this negation is the sublation of the spatial not-A, the raising and transforming of it into the specific spatial not-A of $A$. This new content induces a new form, the specific not-A of $A$ is the environment of $A$ without which neither A nor specific spatial not-A could exist.

In dealing with two identities of opposites, $A$ and its environmental not-A, dialectical logic is concerned with the relation of categories reflecting levels of reality as subject and object, internal and external, attribute and property, necessity and accident, time and space. Each subject is an object -- each A is itself an environmental not-A of its opposite -- and each object is a subject -each environmental not-A of $A$ is in itself an $A$. What is internal within $A$ externalizes itself over against its environmental not-A and becomes internal to the not-A of $A$, and vice versa. The attributes of $A$ and the attributes of the environmental not-A determine the properties of $A$ in relation to not-A, and vice versa. Internal temporal necessity gives rise to external spatial accident 
Fig. A: Structure of Temporal Process in General (1st level of dialectical logic)

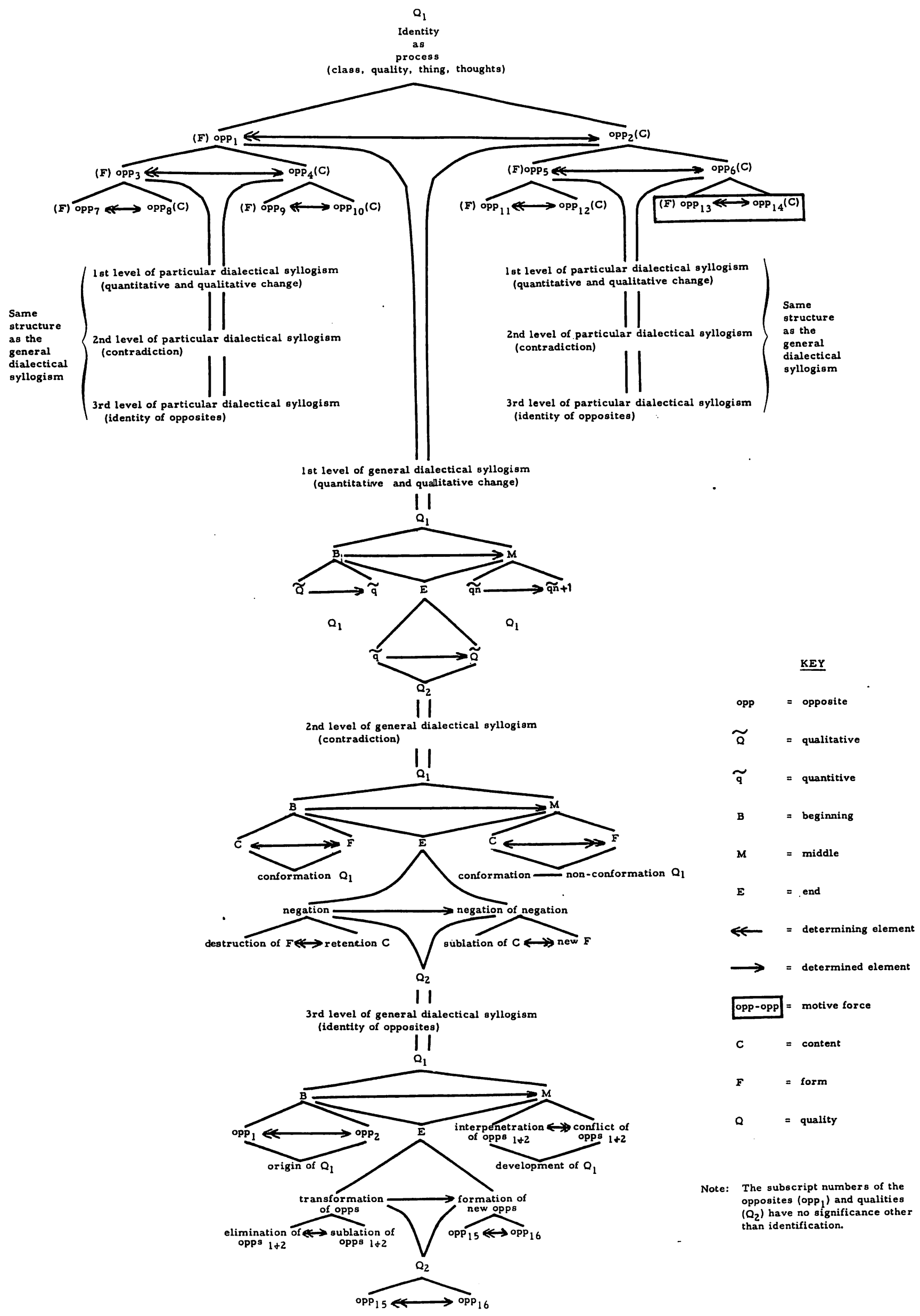


which in turn is necessary for the internal temporal necessity of the not-A of $\mathrm{A}$, and vice versa. Time is the internal development of A from its beginning to its end, but this temporal development acts spatially on and becomes an internal part of, the temporal development of the specific spatial not-A, and vice versa. Here in the dialectic of the external or spatial interconnections of $A$ and its specific spatial not-A, there is the reflection of the transformations of subject into object and object into subject, of internal into external and external into internal, of attribute into property and property into attribute, of necessity into accident and accident into necessity; and finally of time into space and space into time.

When these two identities in spatial relation, the $A$ and its specific not-A, are viewed as opposites within an inclusive identity, they are transformed into an identity of opposites in regard to which all the laws and generalizations as well as levels of the dialectical syllogism, relevant to such identities pertain. Therefore what is a spatial relation at one level is a temporal relation at another, and vice versa. For a graphic representation of this see figure $B$.

With the temporal and spatial negation and negation of negation of the laws of formal or classificatory logic, the entire dialectic is present, if only in outline form. Dialectical logic is seen to be the structure of the temporal and spatial interconnections of processes in general. This most abstract structure can now be applied to the more concrete, though still abstract, structuring of those sciences relevant for an understanding of the historically constituted conditions that give rise to the psychological syndrome of alienation.

Logical structure, whether of classes or of processes, is applicable to the structuring of the categories of any given phenomenon or science thereof because it is the reflection by human consciousness through language of the levels of reality at which society in its practical activity--for example in industry and in science -- is dealing with the world. The practical activity of society is both the origin and verification of man's reflection of the structure of levels of reality. Logic is the reflection of the structure of the structure of reality at the level at which society is dealing with it. It is the generalization of the structure of classes and processes as they have been reflected and verified in and through the various sciences. The ultimate test of the truth of reflection is its effectiveness in guiding man's practical activity in the adaptation of the environment to man's needs and aspirations. Logic is a most abstract level of man's reflection of the world and of himself and is a true reflection in so far as it corresponds to the levels of the world at which man is working with it.

Underlying both classificatory or formal logic and genetic or dialectical logic is the reflection theory of knowledge and the correspondence theory of truth. These theories have always underlain man's practical and theoretical activity. The structuring of the categories of gnosiology, of, that is, cognition and epistemology, is one of the main tasks of dialectical logic.

Logic has ontological as well as logical reference. It is expressed in the sciences either implicitly or explicitly. Implicitly when the scientists are unaware of its employment; explicitly when they are aware of it -- and to the degree to which they are so aware. Logic in both its formal and dialectical stages is fully applicable to the sciences because it is already embodied and 


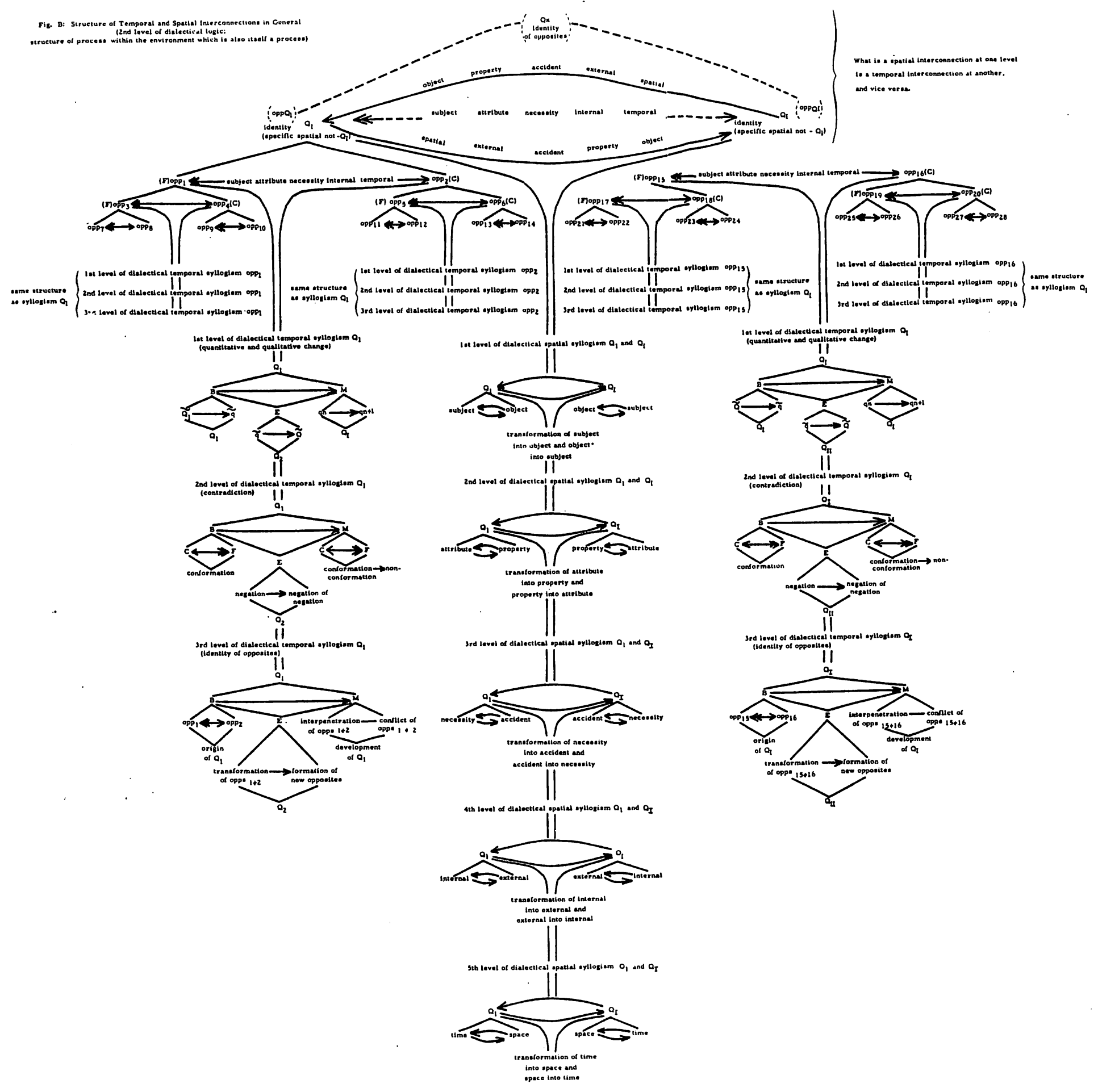


expressed in them. The application makes explicit what is implicit. Sciences reflect levels of the world and these levels are both classes and processes at one and the same time. Thus the two levels of logic are always and everywhere embedded in the sciences, in so far as they truly reflect aspects of objective reality. The application of logic to the categories of the sciences is not a matter of forcing the latter into a mold, but of expressing the abstract structure concretely embodied in the scientific theories, laws and facts.

3.

The sciences most relevant for understanding the existential conditions that have given rise to the psychological syndrome of alienation are history, political economy and psychology. History in the broad sense includes the history of mind and economic and political organization. The most relevant history is the history of the production stage over the past ten thousand years. Still more relevant to the understanding of alienation is the history of capitalism and in particular the history of monopoly capitalism in the 20th century. To grasp the nature of the production period as a whole, however, it must be set within the entire course of human history, past, present and directional future.

The first stage of human history was the gathering stage lasting some two million years. In this extended period man evolved biologically and physiologically as a species embodied genetically in the individual. But this biological and physiological evolution of the specific individual took place only over against and in inseparable connection with the development of a historically constituted society based on weapon and tool making with its concomitant skills. Forms of economic and social organization developed and along with them language and logic leading to reflection, in thought and emotion, of the environment at the level at which man was dealing with it by means of his skills and tools. Social consciousness, the consciousness of society embodied in institutions and social knowledge, developed in closest conjunction with social being. In the gathering stage of human history, the basic laws of evolution and historical development became apparent: First, social being determines social consciousness while the latter acts back again on the former; second, social being and social consciousness are not only organizing classificatory categories of society, but constitute the organizing pair of opposites within the identity or quality which is society; third, the structure of social being is a structure of paired categories including the forces and relations of gathering with its tools, raw materials and skills on the one hand and its relations of man to the means of gathering and of man to man, on the other; fourth, that the motive force of human history at the gathering stage lies in the forces of gathering; fifth, that the individual person becomes a human being only by means of a double potentiality including on the one hand the specific human innate biological and physiological structure and function with which he is born and on the other, the internalization via physiologicalization through participation in the externally existing social heritage (language, logic, thoughts, emotions, institutions, arts, rituals, mores, skills, etc.) embodied in the society into which he is born. The dialectical structure of the society and of the individual as on-going closely interconnected processes characterized by pairs of opposites, exhibit the features of non-antagonistic contradictions. The common ownership of the means of gathering is the decisive non-antagonistic contradiction. This is reflected in the social consciousness and in the consciousness of the individual. Psychologically, the 
'motions of the individual, internalized from his society, conform to the ideas of thcir objects: fearing what society confirms as fearful and expressing that fear within the bounds of socially determined limits; hating what is socially determined as hateful within the allowed forms of expression: loving what is socially determined as loveable, and so on. The syndrome of alienation as we know it today, was nowhere extant in the gathering individual. His fear, hate, love was characteristically interconnected with the social knowledge of the object of the emotion and with the socially determined expression of the emotion. Hence, his fear, for example, did not become objectless and transform into anxiety. He was an integrated individual, in ideation and emotion, conforming to the integrated, non-antagonistic social being and social consciousness of his society.

The direction of development of the gathering stage was toward its transformation into the production stage. While gathering, involving weapons and the animals to be gathered by their means, was the primary mode of supplying food, clothing and shelter, production was a secondary mode. The weapons had to be shaped by means of tools skillfully applied to raw materials. During the two-million-year age of gathering, therefore, the next age of mankind was developing within it. The transformation from the gathering stage to the production stage took place at the point at which production became the primary mode, including gathering within itself -- in the form of the gathering of raw materials as one aspect of production. For a structuring of the gathering age and its transformation, syllogistically reflected, into the age of production, see Fig. C.

The very development of gathering weapons, together with the processing of what was gathered, brought with it the development of that which would eventually replace it. This movement of gathering toward production was at the same time the movement from absolute scarcity toward relative scarcity in which production gave rise to labor producing a surplus over and above the minimum amount of food, clothing and shelter required for the continued existence of the producer. This relative scarcity as relative surplus brought into being relations of production in the form of owners and non-owners of the means of production, the tools and raw materials. This division in turn brought into being the classes based on ownership and non-ownership, thus splitting social being into antagonistic contradiction. The owning class, a small minority, brought into being the state with its legal structure and armed forces to maintain its class position, thus splitting social consciousness into antagonistic contradiction between superstructure and human knowledge. The antagonistic contradictions in the social being of production society brought into being a range of antagonistic contradictions in the social practice and consciousness of the individual living within the society. Thus the transformation from the gathering age of mankind to the production age entailed the transformation from characteristically non-antagonistic contradictions to antagonistic contradictions.

The direction of development of production society is from the production of relative scarcity and relative abundance to the capacity to produce absolute abundance. The United States is rapidly approaching this capacity -- if it has not already done so. At that point the forces of production strain at and eventually break out of the private relations of production, out of, that is, the ever more private ownership of the means of production. The social ownership of the social forces of production would transform the antagonistic contradiction lying at the base of production society into a non-antagonistic contradiction. The 


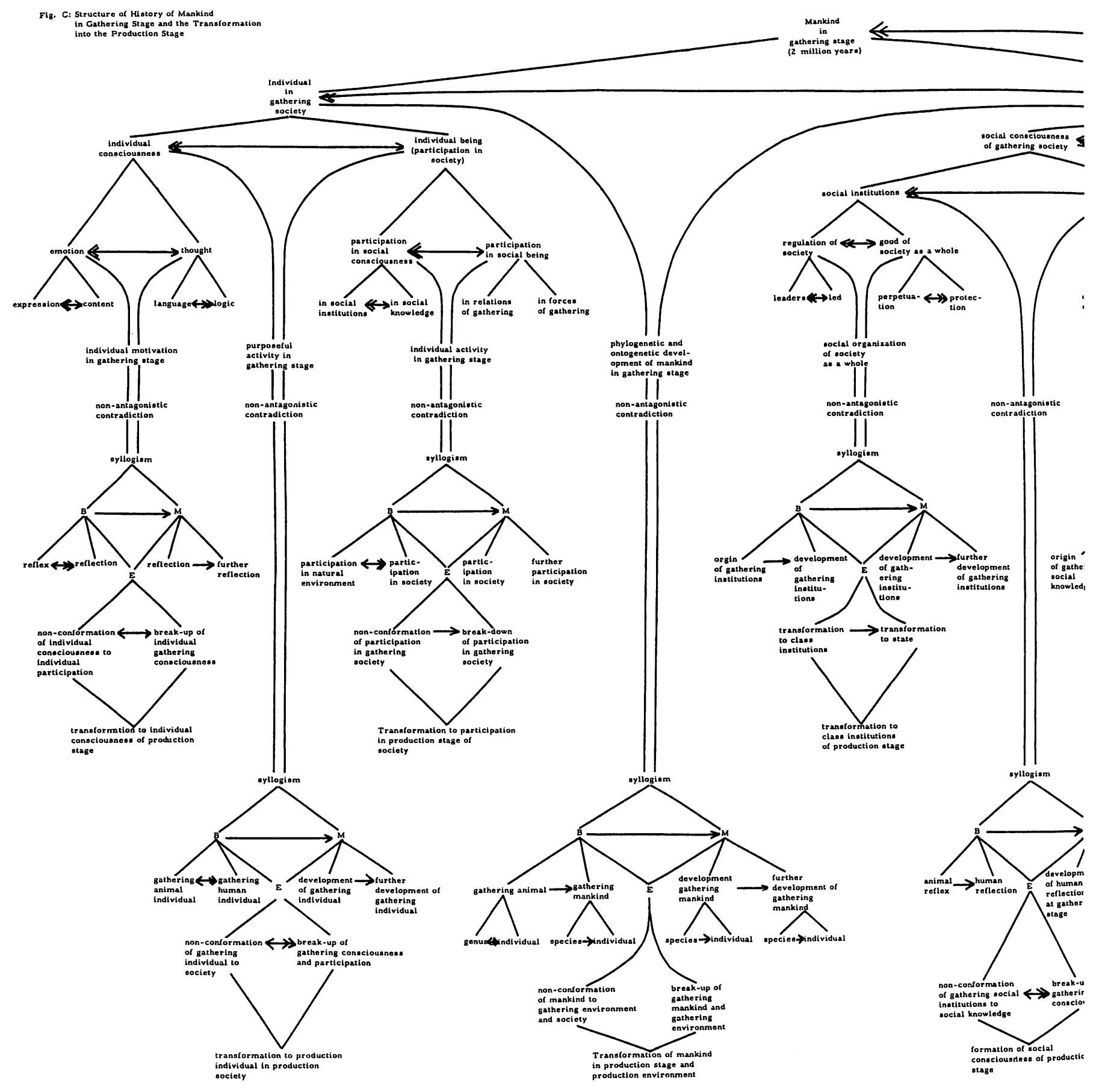


absolute surplus of useful products will be made available to the people as a whole, meaning to each individual. The abundant useful products include not only food, clothing and shelter but also culturally useful products. The reduction of the working day or week made possible by automated, self-regulating machines, will provide the leisure time necessary for creative and self-creative activity of the individual. The age of production transforms into the age of creativity.

Leisure and creativity have developed throughout the age of production as a secondary feature of society and the individual. This is seen in the development of professional art and science from their beginnings in slave society to larger and larger proportions in the final stages of capitalist society. In the age of creativity what was secondary in the production age will become primary. At the same time, of course, the age of creativity will carry within itself the production on which it rests -- just as the age of production carried within itself the gathering on which it rested.

The transformation from the age of production to the age of creativity will bring with it, not only the abolition of private ownership of the means of production, but likewise the elimination of the division of society into antagonistic classes and of the division of social consciousness into superstructure and human knowledge. The social consciousness of creative society will ultimately become identical with human knowledge in its art, science and technological forms, including the organization of production and distribution in the interests, needs and aspirations of the individuals living within the society. The motive power of creative society will in all likelihood reside in the non-antagonistic contradiction between specific levels of knowledge and ignorance constantly transformed on more essential levels. The objective of the creative age will at one and the same time be the advance of social and of individual creativity -- the one being the condition for the advance of the other. The age of creativity will presumably be characterized throughout by non-antagonistic contradictions, the form expanding with the expansion of the content, at both the social and individual levels.

The structure of the age of creativity has nowhere as yet come into being on our planet. The unconditional future tense is employed because we are on the threshhold of this transformation and its coming is unavoidable. Once mankind can produce enough for every individual, then the age of creativity is at hand. The people of the United States have given proof over the past half-century that man can achieve absolute abundance -- even though this very capacity looms as a colossal threat. It looms as a threat precisely because the capacity to produce an absolute surplus is squeezed within the narrow confines of private ownership of the means of production. Thereby American-human victory appears as defeat, and instead of being proud of our achievement, we cringe at its implications within our given society. Break out of the society and the achievement can be celebrated as the great human victory it is.

A philosophical time-span can furnish an overview that will place the brief 10,000 years of the age of production in the setting of human history as a whole -- past, present and future. This overview is graphically presented on the following page. In such a perspective the age of production appears as a brief moment characterized on the one hand by exceedingly rapid change and on the other 
STAGES OF HUMAN HISTORY

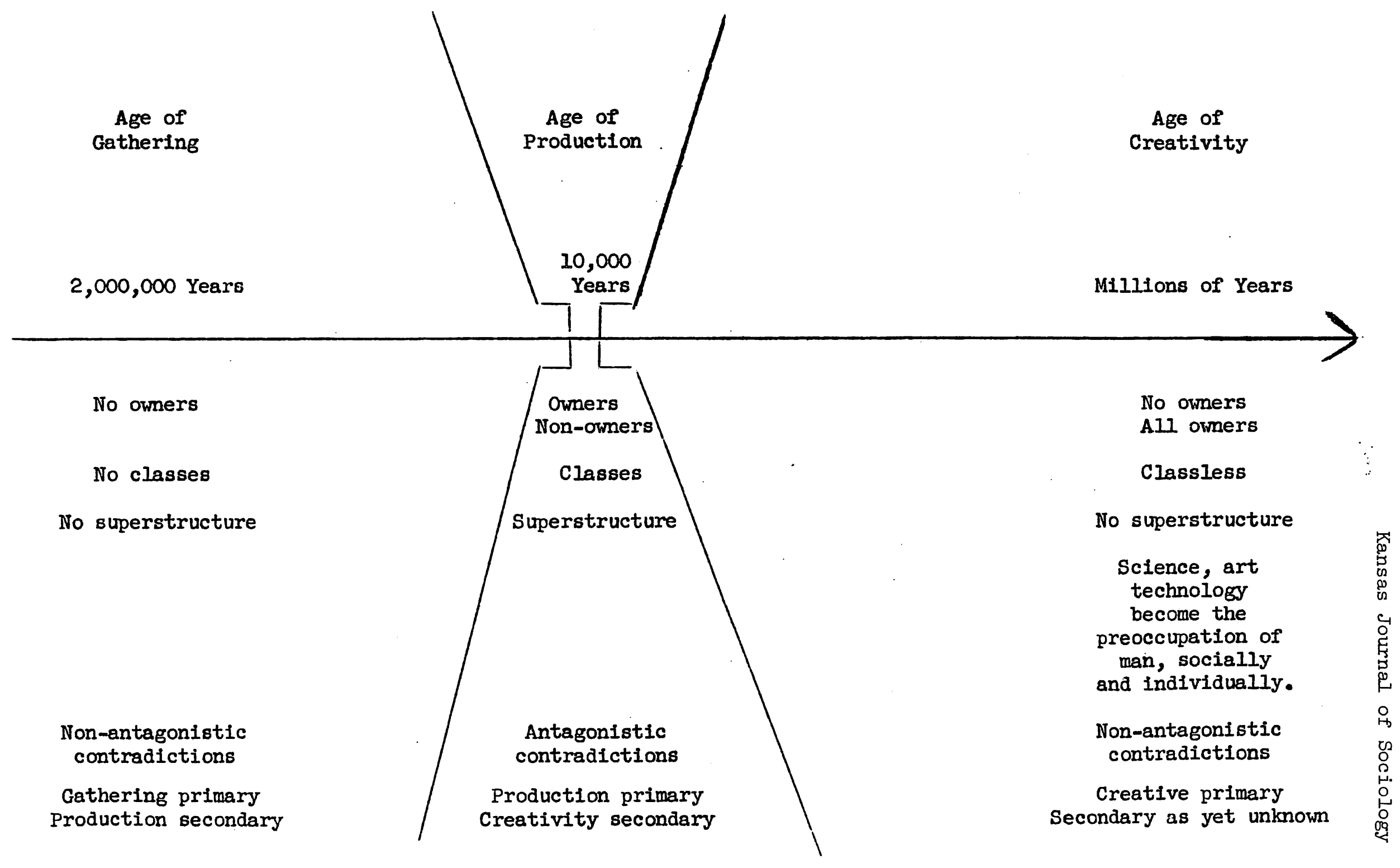


by sharp antagonistic contradictions that appear nowhere else in the course of human history. The relative briefness and rapidity of the changes brought about in the period of production suggests that it may be viewed as the moment of qualitative change from animal-human to human-human -- in fact the transformation from animal to man. The creative society and the creative individual comprise the rully human society and individual. Anything beyond the age of creativity is inconccivable at this time -- unless messages from outer-space are received and decoded which could then conceivably indicate ages beyond creativity, if such messages could be understood at our earthly level of development.

The philosophical time-span, with its indication that antagonistic contradictions within mankind, social and individual, are limited to the age of production, carries with it the implication that the psychological syndrome of alienation, reflecting such contradictions, is likewise limited to this transitional age.

The syllogism of movement from the beginning of the production stage through its slave, feudal and capitalist middle is characterized by a heightening and further heightening of antagonistic contradictions. For example, the relations of production become more and more private, more and more concentrated in fewer and fewer owners, until in monopoly capitalism this shrinkage reaches its apex. At the same time, the forces of production become more and more social, concentrating masses of workers and giant machines in one plant or complex of plants. Thus the content, the forces of production, moves in one direction while the form, the relations of production, moves in the opposite direction. Such sharpening of antagonistic contradictions are found in all spheres of monopoly capitalism.

The monopoly capitalist stage of production society is characterized by antagonistic contradictions in almost all its structure of processes with the notable exception of the forces of production. Even the latter are so interpenetrated by the private relations of production that they exhibit features of antagonistic contradictions, for example, in the separation of labor power from the means of production and their union only through hiring and wages. The means of production become capital and the labor power itself becomes a commodity, as does the product of the two. The product as a use value is interpenetrated with private ownership through expropriation and becomes inextricably interconnected with exchange value.

The dialectical structure of productive society in the nonopoly capitalist stage, including the individual living within it, and the syndrome of alienation is presented graphically in Fig. D.

4.

Marx in his early works tended to call antagonistic contradictions alienations, after Hegel. In his mature scientific works, however, he dropped the term "alienation" as applied to the contradictions within society. The scientific use of the term "alienation," is as a particular kind of distorted reflection in the human mind of the antagonistic contradictions characteristic of the production age. Alienation, therefore, is a category of individual consciousness and of ideological superstructural social consciousness within the productive period, but particularly in capitalism and more particularly in monopoly capitalism. 


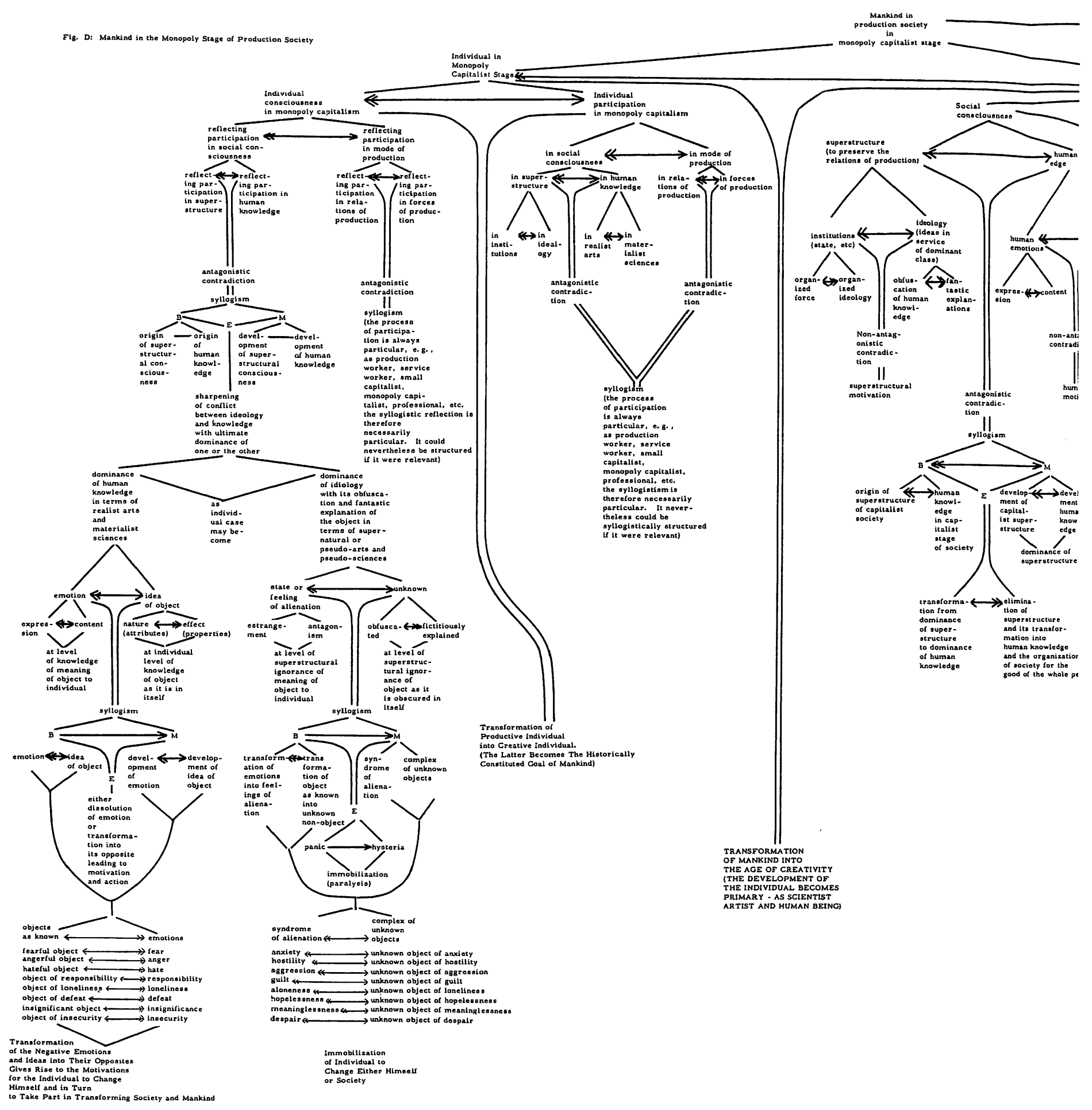


The alienation syndrome is a distorted reflection of the antagonistic contradictions in contemporary capitalist society. This distorted reflection is found first in the institutions and ideologies of the superstructure erected over the base, the particular relations of production characteristic of monopoly capitalism. The primary function of the superstructure is to serve and preserve the base. One of the forms of such service and preservation lies in the obfuscation of the reflection of the antagonistic contradictions of the society. The most effective and prevalent form of obfuscation is ideologically distorted reflections of these contradictions. Such reflection is the rationalization of and apology for antagonistic contradictions. An example would be the factor theory of alienation and its alienating conditions. Another would be the transformation of the very real historically constituted antagonistic contradictions into the metaphysical human predicament or human condition -- or into the proposition that progress in civilization leads to neurosis and ultimately to psychosis.

In any event, the effect of all the varied superstructural fantastic and distorted reflections of the antagonistic contradictions in monopoly capitalism is to render the objects of knowledge into unknown objects, into non-objects, and the corresponding emotions into objectless vague feelings. The objectless feelings, such as anxiety, hostility, aggression, aloneness, hopelessness, meaninglessness, despair, guilt, and so on, constitute the syndrome of alienation in the individual. In each symptom of the syndrome, there is the same transformation from a dialectically close interconnection between emotion and its object as truly known to a separation of these emotional and ideational opposites. This separation tears apart what in fact can only exist together. Thus the real emotion and the truly human object are transformed on the one hand into objectless feelings and on the other into unknown or misconceived vague objects. These feelings of alienation can lead to depression, panic and paralysis of emotion, intellect, motivation and activity -- which in turn feed and reinforce the original feelings. Such feelings are, of course, an effective means of serving and preserving the base of society. This is particularly true when it occurs in the cultural and intellectual community. Our art, novels, theatre and psychology, not to mention philosophy, are replete with just such a syndrome. In this manner a large section of the cultural and intellectual community serves and preserves the base by enhancing the fictional reflection of the antagonistic contradictions in our society.

Obfuscation of human knowledge occurs in many ways. First is the ideological and institutional inadmissibility of large areas of knowledge, including entire sciences such as materialist philosophy, dialectical logic, materialist history, political economy, the physiology of higher nervous activity, the science of human psychology, the science of ethics and morality, among others. Another is the undercutting of science by means of epistemological arguments directed against truth as correspondence, at once relative and absolute, of ideas to their existential objects. Once obfuscation of established human knowledge has been achieved, the way is open to all manner of fantastic reflections, theories and explanations, ranging from historicism through economic and social apologetics to psychoanalytical and existential psychologies and philosophies.

One of the outcomes of such obfuscation and fantastic explanation is the splitting of emotions from their objects as known at the level of knowledge of the individual. Emotions, the significance to the individual of objects as he knows them to be in themselves, cannot exist apart from such objects. Separated 
from their objects as known, the emotions cease to be emotions and are transformed into objectless feelings or states. The negative emotions when separated from their objects as known become the symptoms that together form the syndrome of alienation. Once split off from their objects the emotions (now objectless feelings or states) cannot be transformed into their opposite positive emotions which in turn could give rise to motivations and eventually actions to change the self and the society. The symptoms of alienation, as objectless feelings or states, immobilize the individual, blocking motivation and action purposefully directed toward self-change and social change. This imnobilization is the ultimate product of ideological and institutional obfuscation.

Alienation is an identity of two sets of opposites, one external and the other internal. Alienation is the external opposite of the integration of emotion and its object as known. At the same time, it is the identity of opposites on the one side of vague feelings and on the other of unknown or distortedly reflected objects. The total effect of alienation is estrangement from and antagonism toward all possible unknown objects, including nature, world, society, other people, opposite sex, values, standards, knowledge, reason, emotional involvement, action, and finally self. The effect of estrangement and antagonism as embodied in objectless feelings is immobilization: panic, hysteria and paralysis.

The central symptom, the symptom that plays the organizing role in the syndrome of alienation, is anxiety. It is even said that we live in the "age of anxiety." An analysis of this symptom will serve to exemplify the meaning of alienation as a very real psychological phenomenon in contemporary society.

Anxiety is, in appearance, objectless fear. But fear separated from the fearful object ceases to be fear and becomes anxiety. Anxiety therefore is, more essentially, dread of an unknown and fantastically distorted dreadful object or complex of such objects. The identity of opposites within anxiety is on the one hand dread and on the other the dreadful object at the individual level of ignorance and misconception. The external opposite of anxiety, as of all the symptoms comprising the syndrome of alienation, is the superstructure of capitalism and more particularly of monopoly capitalism. The superstructure, through its institutionalized ideologies, fosters and inculcates obfuscation and distortion of the true reflection of the objects of fear. One of the ideological functions of the superstructure is to furnish rationalizations and apologetics for the fearful antagonisms inherent in the final phase of capitalism. These rationalizations and apologetics obfuscate and distort the fearful objective antagonisms into dreadful objects which in turn transform fear into dread. Dread is expressed physiologically and behaviorally as immobilization, panic, hysteria and paralysis -- of nerves, feelings, motivations and activity. Dread cannot be transformed into courage, but leads rather to "fear and trembling" verging on self-destruction, literally suicide.

Anxiety, with its ideologically induced dread and dreadful object, can be transformed into courage only by first transforming itself into fear. The transformation of anxious dread into fear can be accomplished only by prior transformation of the dreadful object into the fearful object in which the fearful nature and effects (attributes and properties) of the object are known and evaluated as to degree of fearfulness. Deepening knowledge of the fearful object moving from abstract to concrete and from appearance to essence (through social participation), can transform fear to a level at which it can be overcome. This identity of 
opposites, fear and the overcoming of fear, is courage. Courage is the positive opposite emotion of fear, into which fear can be transformed.

To transform anxiety into fear requires first the breaking up of the ideological misconceptions comprising the dreadful object; and second the application of human knowledge to the dreadful object thereby, through a process of cognition and participation, transforming it into the fearful object. The transformation of fear into courage entails the further application of human knowledge, through a process of cognition and participation, aimed at transforming the little-known object of fear into the wel1-known object.

Human Knowledge, the thus far developed knowledge organized in all the sciences and the arts, can transform anxiety into fear and fear into courage. Superstructual ideology, the obfuscation of human knowledge and the substitution of apologetics, can transform courage into fear and fear into anxiety. The latter is the genesis of the organizing symptom of the syndrome of alienation; while the former is the genesis of courage which is the organizer of the human integrative emotions that can motivate and activate the individual to change himself and to help change the society. It is little wonder, then, that the superstructural preservation of the society requires the ideological transformation of courage into fear and fear into anxiety, dread, panic, hysteria and paralysis; or in general that it requires the transformation of the emotions of integration into the symptoms of alienation. Progress toward the transformation of the individual and society requires the reversal of this process.

For a graphic presentation of the structure of anxiety as the organizing syndrome of alienation, together with the structure of fear and the syllogistic reflection of its transformation into courage, see Figs. $E_{1}$ and $E_{2}$ (following two pages).

The dissolution of the syndrome of alienation can be achieved on two levels, the individual and the social. The individual can dissolve the alienation syndrome by reuniting his emotions, each with its appropriate object. He can do this by breaking through the fantastic and distorted reflections of the non-object and transforming it into a known object. He can transform it into a known object by mastering the social knowledge relevant to that object. The level of the emotion, in both its content and expression will then conform to his level of knowledge of the object. When the emotion does not so conform, he will take this as an indication that he must strengthen and deepen his abstract and concrete mastery of the the social knowledge available to hin. In short, the transformation of the alienation syndrome at the individual level is a matter of reeducation. $\operatorname{Re}-$ education involves a two-fold task of breaking through distorted reflection and substituting true knowledge. It requires, that is, the transformation of the levels of participation of the individual in society. More particularly, it involves rejection of fantastic ideologies and participation in the knowledge amassed down the ages by mankind -- and, under the motivation engendered by closely related emotion and knowledgeable ideation, putting that knowledge to work.

The dissolution of the syndrome of alienation at the social level entails the transformation of society. Such transformation means the elimination of the primary antagonistic contradiction between the private ownership of the means of production and the social organization of the forces of production. All the other antagonistic 
Fi $E^{r}$. $E_{1}$ : Structure of Fear in Relation to Fearful Object and the Transformation into Courage
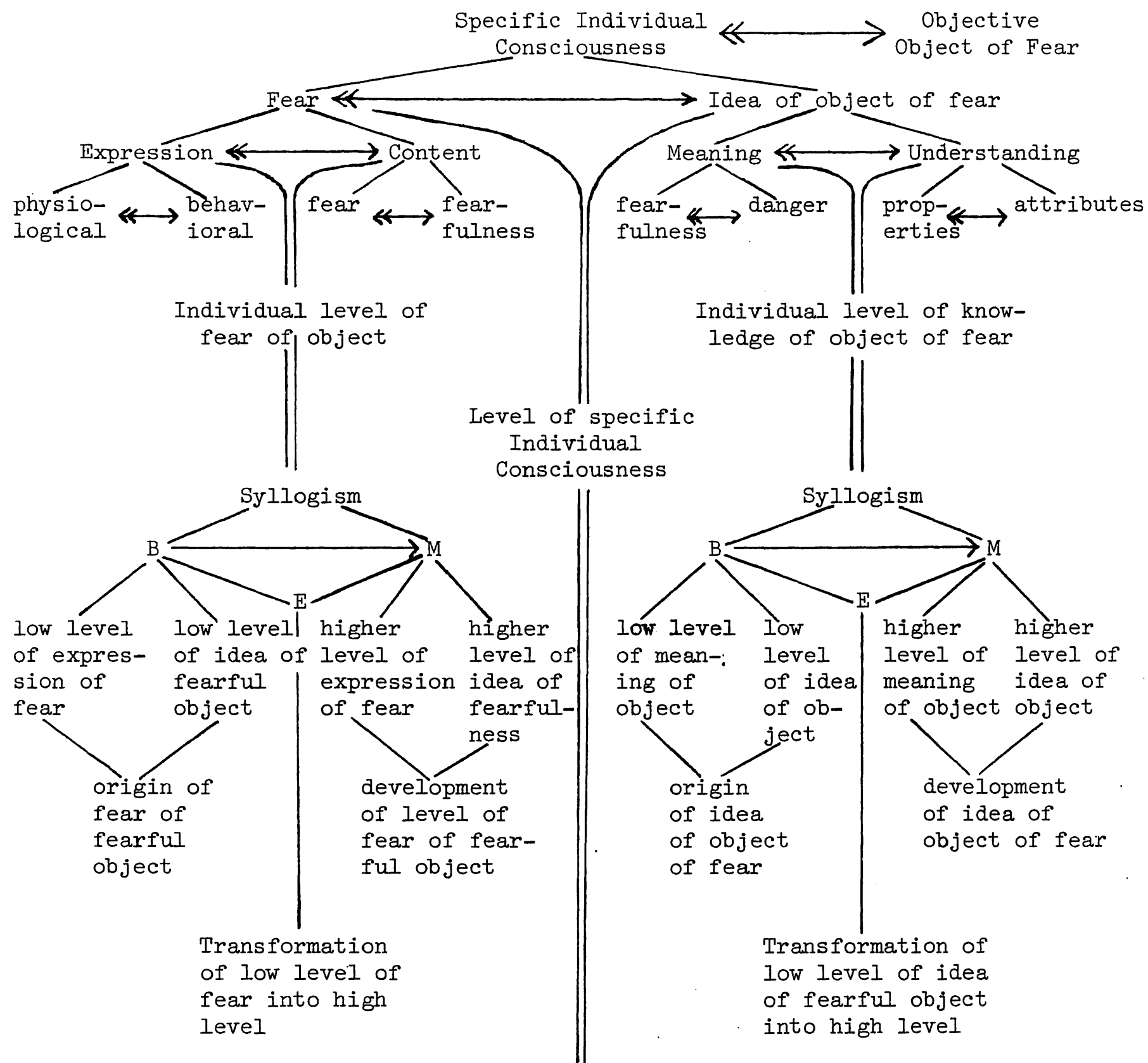

Syllogism

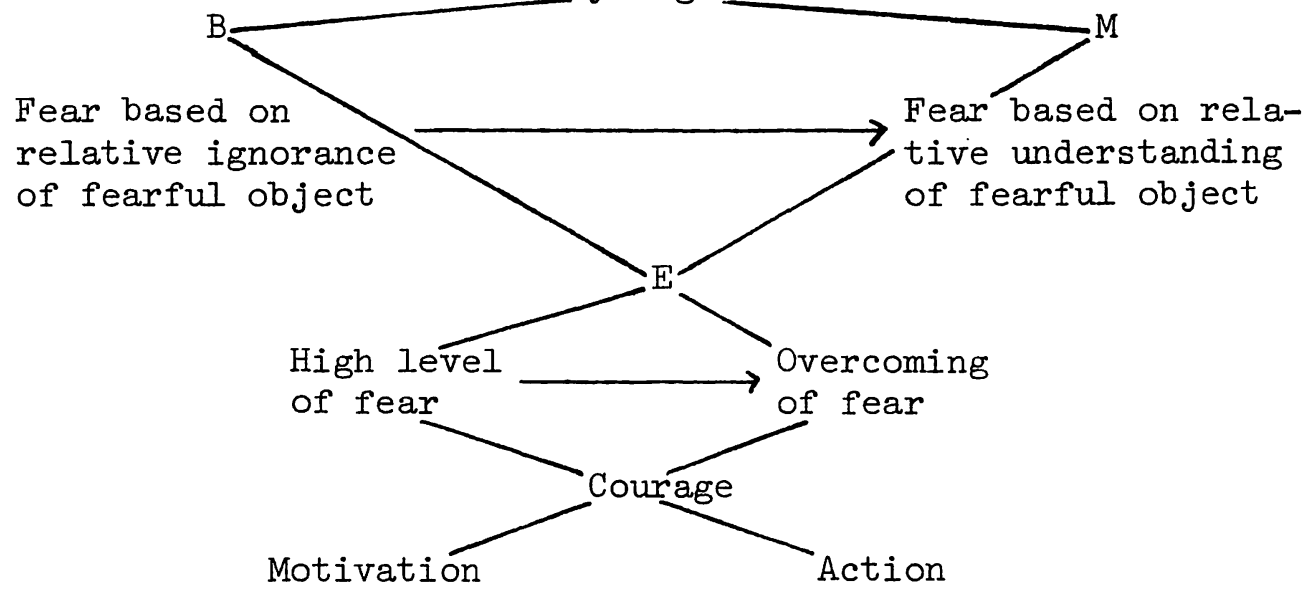



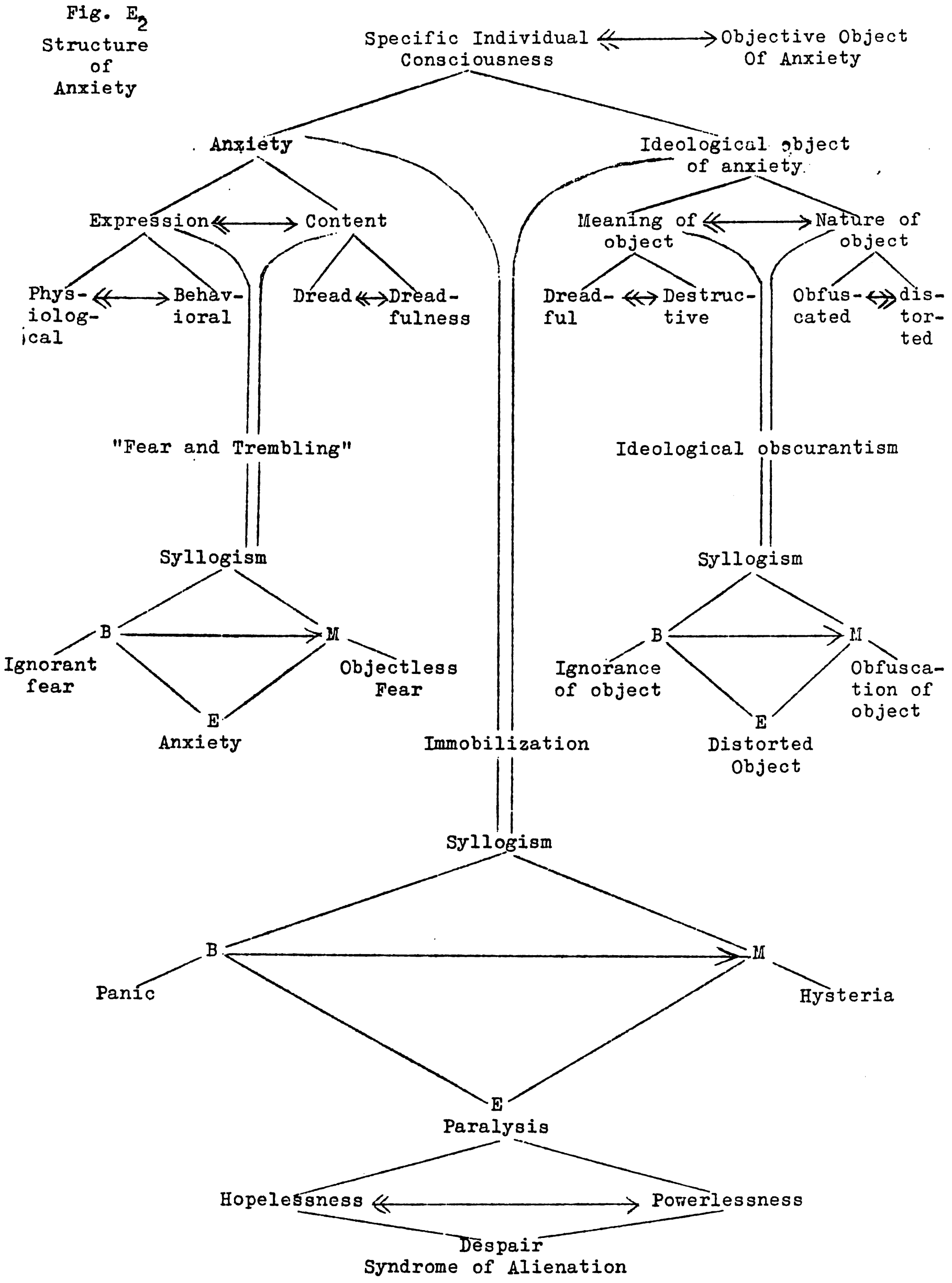
contradictions can then begin to be eliminated as the new society develops quantitatively. The new society will in time become the creative age of mankind, built upon the achievements of the gathering and production stages. Prediction of the creative age is firmly based on the current and particularly American achievement of the capacity to produce not only the food, clothing and shelter in sufficient quantity for all, but also the means of creativity -- the cultural means and the leisure to employ them. We in the United States especially are on the threshold of this transformation. Indeed it is the only resolution possible, not only of the syndrome of alienation, but more fundamentally of the intolerably sharp antagonistic contradictions permeating our society.

The identity and interpenetration of the two opposite resolutions of the syndrome of alienation are readily apparent. The social resolution requires the individual resolution -- the freeing of the individual from ideological distortions and the acquisition of the knowledge that, put into action, will build the creative society.

\section{Footnotes}

$1_{\text {This paper was read at the annual meeting of the American Philosophical }}$ Association, Chicago, April 29, 1965. The script was edited by Rosalind Wells, charting done by Lucy Paley, and production by Jean Wells.

2 That dialectical logic has been a victim of alienation also in the Soviet Union is indicated by M. M. Rosental in his book entitled Dialectical Logic (Moscow, 1960) in which he states that "We have paid a great deal of attention to formal logic and almost none to dialectical logic.

\section{References}

Bowden, Edwin T.

1961 The Dungeon of the Heart: Human Isolation and the American Novel.

New York: Macmillan.

Buber, Martin

1948 Between Man and Man. New York: Macmillan Company.

1949 Paths in Utopia. London: Routledge and Kegan Paul.

Engels, F.

1936 Anti-Duhring. New York: International Publishers

1955 Ludwig Feuerbach. New York: International Publishers.

1960 Dialectics of Nature. New York: Internationa1 Publishers.

Feuerbach, Ludwig

1846 Sammtliche Werke. Leigzig: Otto Wigand.

Fromm, Erich

1961 Marx's Concept of Man. New York: Frederick Ungar Publishing Company. 
Halmos, Paul

1953 Solitude and Privacy: A Study of Social Isolation, Its Causes and Therapy. New York: Philosophical Library.

Harris, William T.

n.d. Hegel's Logic. Chicago: S. C. Griggs.

Hege1, G. W. F.

1892 The Science of Logic (Shorter Logic of the Encyclopedia.)

Oxford: The Clarendon Press.

1899 The Philosophy of History. New York: The Colonial Press.

1949 The Phenomonology of Mind. New York: Macmillan.

1951 Science of Logic. New York: Macmillan.

1955a Lectures on the History of Philosophy, 3 vols., E. S. Haldane (tr.). London: Routledge and K. Paul.

1955b Philosophy of Right. T. M. Knox (tr.). Oxford: Clarendon Press

n.d. Doctrine of Formal Logic. Oxford: Clarendon Press.

11.d. Philosophy of Mind. Oxford: The Clarendon Press.

Hodges, Donald Clark

1964 "The Unity of Marx's Thought." Science and Society 28, no. 3: 316-323.

Gregor, A. James

n.d. "Marx, Feuerbach and the Reform of the Hegelian Dialectic." Science and Society 29 , no. 1.

Jackson, T. A.

1936 Dialectics. London: Lawrence and Wisehart, Ltd.

Josephson, Eric and Mary Josephson

1962 Man Alone: Alienation in Modern Society. New York: Dell Publishing Co.

Lenin, V. I.

1947 Materialism and Empirio-Criticism. Moscow: Foreign Languages Publishing House.

1961 Philosophical Notebooks, Collected Works, vo1. 38. Moscow: Foreign Languages Publishing House.

Loewith, $\mathrm{K}$.

1953 Von Hegel zu Nietzsche. Zürich/Wien: Europa Verlag.

Mannheim, Karl

1940 Man and Society. London: Kegan Paul, Trench Trubner and Company. 
1943 Diagnosis of Our Time. New York: Oxford University Press.

1946 Ideology and Utopia. New York: Harcourt, Brace and Company.

Mao tse tung

1953 On Contradiction. Peking: Foreign Languages Publishing House.

Marx, Karl and F. Engels

1947 The German Ideology. Moscow: Foreign Languages Publishing House.

1956 The Holy Family. Moscow: Foreign Languages Publishing House.

Marx, Kar1

1931 Capital. New York: Charles H. Kerr and Company.

1938 Poverty of Philosophy. New York: Charles H. Kerr and Company.

1964 The Economic and Philosophic Manuscripts of 1844. Dirk Struik (ed.)

New York: International Publishers.

Mills, C. Wright

n.d. Images of Man: The Classic Tradition in Sociological Thinking. New York: George Braziller, Inc.

Pappenheim, Fritz

1959 Alienation of Modern Man. Monthly Review Press.

Rosental, M. M.

1960 Dialectical Logic. Moscow.

Sartre, Jean-Paul

1963 Search for a Method. New York: Knopf.

Stace, Walter $\mathrm{T}$.

n.d. The Philosophy of Hegel. New York: Dover Publishers.

Sykes, Gerald, ed.

1964 Alienation. New York: George Braziller, Inc.

Tucker, R. C.

1961 Philosophy and Myth in Karl Marx. Cambridge. Cambridge University Press.

Venable, Vernon

1964 Human Nature: The Marxian View. New York: Knopf.

(no author)

1960 "On Hegel's theory of alienation and its historic force." Tulane Studies in Philosophy 9, Studies in Hege1: 50-100.

(no author)

1964 "Alienation and socialism." The New Hungarian Quarterly (Budapest) 15.

(no author)

1961 "A symposium: Alienation and the search for identity." American Journal of Psychoanalysis 21, no. 2. 